\title{
Orthodontic Management of Occlusal Prematurity in Early Mixed Dentition
}

\author{
Maen Mahfouz, Yara Mahfouz \\ Department of Orthodontics and Pediatric Dentistry, Arab American University, Jenin, Palestine \\ Email: maenmahfouz@gmail.com, dr_cuteee@yahoo.com
}

Received 22 January 2015; accepted 10 February 2015; published 16 February 2015

Copyright @ 2015 by authors and Scientific Research Publishing Inc.

This work is licensed under the Creative Commons Attribution International License (CC BY). http://creativecommons.org/licenses/by/4.0/

(c) (i) Open Access

\begin{abstract}
Premature contact is one of the most well-known occlusion disorders and can interfere mandibular movement remarkably. The masticatory system has ability to respond with the wide range of adaptive modalities. These adaptations can be functional, structural and/or behavioral. Therefore, this system, like any biological system, cannot be viewed as a rigid and immutable. This paper presents a clinical case which is demonstrating orthodontic management of occlusal prematurity in early mixed dentition by using a protrusive arch wire.
\end{abstract}

\section{Keywords}

\section{Orthodontic Management, Occlusal Prematurity, Early Mixed Dentition}

\section{Introduction}

The masticatory system is a functional unit composed of the teeth; their supporting structures, the jaws; the temporomandibular joints; the muscles involved directly or indirectly in mastication (including the muscles of the lips and tongue); and the vascular and nervous systems supplying these tissues. Functional and structural disturbances in any one of the components of the masticatory system may be reflected by functional or structural disorders in one or more of its other components [1] [2]. However, there is a lot of evidence that the masticatory system has ability to the wide range of adaptive modalities. These adaptations can be functional and/or structural and may respond to transient and/or permanent demands. Therefore, this system, like any biological system, cannot be viewed as a rigid and immutable [2] [3].

Knowledge of how the mandible moves during mastication has greatly influenced procedures in clinical dentistry. Historically, an understanding of mandibular movement was considered important in removable prosthodontics. Later, this information was used in the design and setting of articulators, and in the design of the dentures and denture teeth themselves. Today the importance of jaw movements has become apparent in fixed 
prosthodontics, periodontics, orthodontics, and in the diagnosis and treatment of pain disorders of the masticatory system [2] [4].

In regard to the occlusion of the teeth, there are two concepts to be recognized; the first is the morphological or anatomical concept as the name implies an occlusion based on the forms of the teeth while the second is the physiologic concept. The physiologic occlusion is a living-dynamic as it participates as one of the components of the masticatory system.

Abnormal functional relationship of the teeth may vary in degree of abnormality from mild to extreme. In the first instance certain teeth may occlude slightly in advance of the other teeth. This is premature contact of the teeth. This condition may also exist in the functional movements of the mandible during mastication [5].

Dental professionals must consider the importance of occlusal contacts for the success of dental treatment, maintaining occlusal stability and orofacial harmony, as occlusal interferences may implicate potential damages to the whole stomatognathic system, which includes teeth, supporting structures, neuromuscular system and temporomandibular joints [6]-[12].

This paper presents a clinical case which is demonstrating orthodontic management of premature contacts in early mixed dentition.

\subsection{Case History}

A 7-year-old boy attended to my private orthodontic clinic with chief compliant of lower anterior teeth overlapping of upper anterior teeth. He was in early mixed dentition stage. In the extraoral lateral view, the patient profile was straight while lip profile was reversed giving the appearance of class III (Figures 1-3).

The intraoral examination revealed a forward shift of the mandible, with a marked class III molar relationship and an anterior crossbite (Figures 4-6).

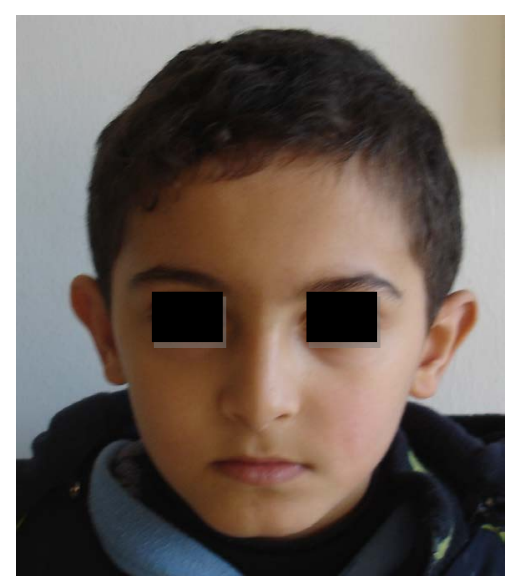

Figure 1. Frontal-extraoral view.

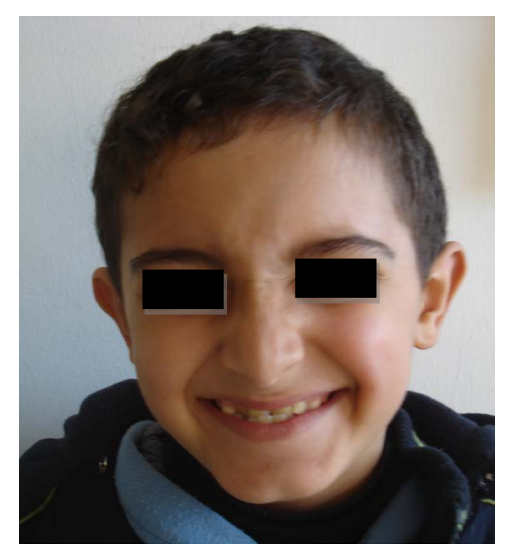

Figure 2. Smile view. 


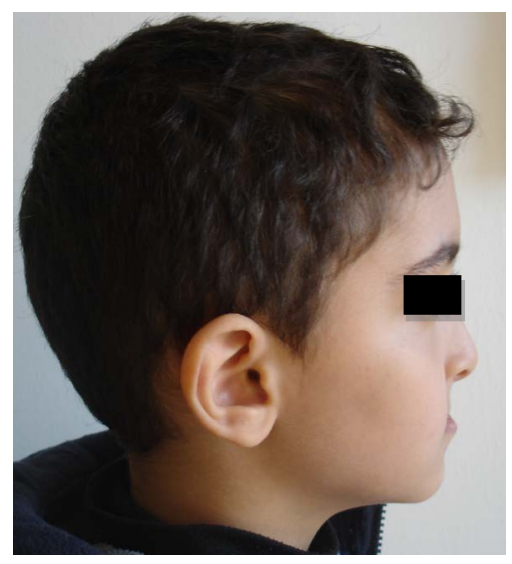

Figure 3. Profile view.

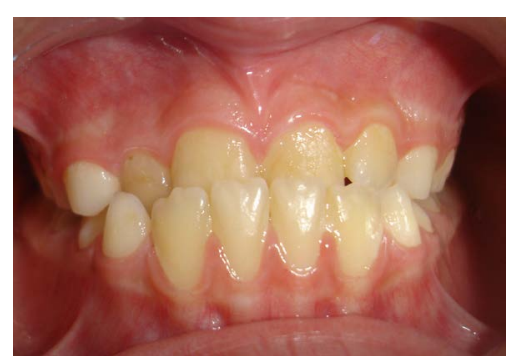

Figure 4. Frontal-intraoral view.

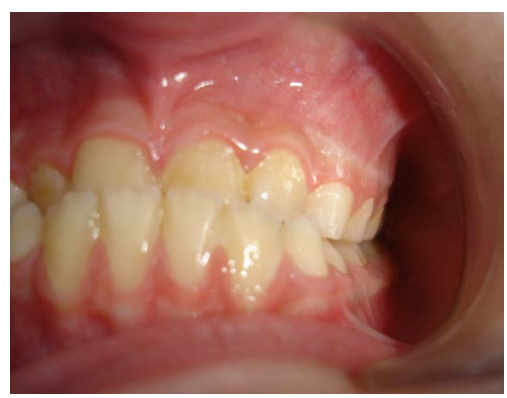

Figure 5. Left side-intraoral view.

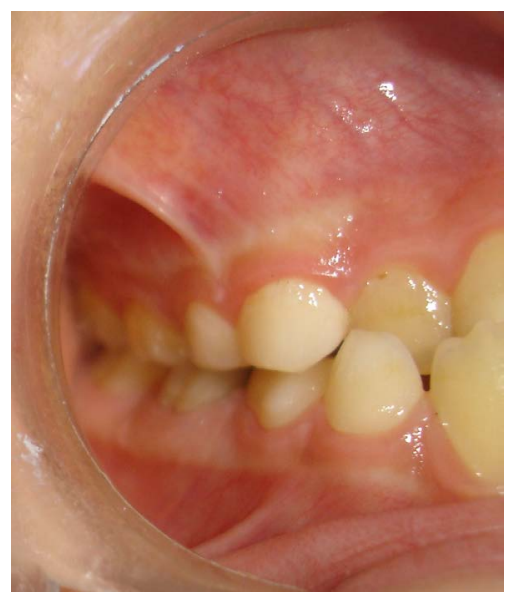

Figure 6. Right side-intraoral view. 


\subsection{Diagnosis}

The clinical examination revealed retruded upper lip with protruded lower lip giving the view of deficient mid face as seen in class III. The upper incisors retroclined and spaced while lower incisors slightly proclined. An anterior crossbite in the presence of a forward mandibular displacement and functional shift to the left side due to premature contact between upper and lower central incisors, class III malocclusion with reverse overjet and negative deep overbite. The starting point in diagnosis and treatment of this case was by establishing centric relation through guiding the mandible into centric relation rather than centric occlusion and then initial contact with the teeth occurs so an edge to edge anterior incisor contact with posterior open bite indicating Pseudo class III (Figures 1-7).

Cephalometric analysis indicated a mild class III malocclusion characterized by a little mandibular protrusion, maxillary retroclined incisors (ANB $=-1$ degree, Wits $=-6 \mathrm{~mm}, \mathrm{I}-\mathrm{SN}=100$ degree) (Figure 8, Figure 9) (Table 1).

Treatment objectives: forward movement of 11 maxillary incisors, eliminating functional shift ,mandibular displacement, premature contact, enhancing normal lip profile, achieving class I molar relationship and canine relationship with ideal overjet and overbite.

Treatment plan: fixed orthodontic treatment by using protrusive arch wire for the forward movement of 11 without raising the bite.

\subsection{Treatment Procedure}

Treatment started so a bondable tubes placed on the buccal surfaces of upper first permanent molars on both sides with brackets (slot 22) placed on the labial surface of the upper central incisors. Then placement of upper

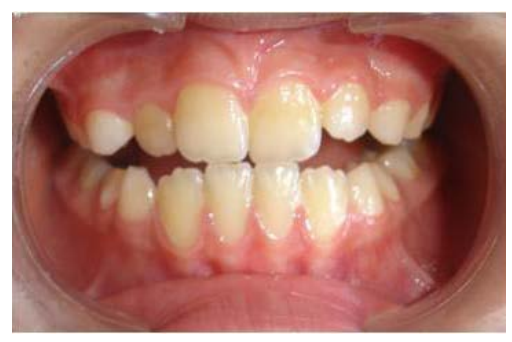

Figure 7. Initial contact between teeth in centric relation.

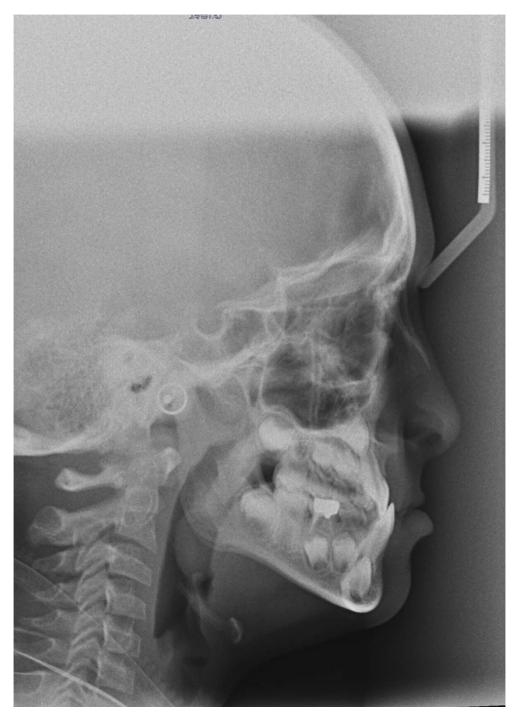

Figure 8. Lateral cephalometric radiograph. 
Table 1. Cephalometric measurements of the patient.

\begin{tabular}{ccc}
\hline Cephalometric values & BEFORE & AFTER \\
\hline SNA & $82^{\circ}$ & $82^{\circ}$ \\
SNB & $83^{\circ}$ & $81^{\circ}$ \\
ANB & $-1^{\circ}$ & $+1^{\circ}$ \\
GoMe-SN & $34^{\circ}$ & $36^{\circ}$ \\
FMA & $24^{\circ}$ & $26^{\circ}$ \\
I-SN & $100^{\circ}$ & $109^{\circ}$ \\
IMPA & $90^{\circ}$ & $88^{\circ}$ \\
I/I & $137^{\circ}$ & $131^{\circ}$ \\
Wits & $-6 \mathrm{~mm}$ & $-1 \mathrm{~mm}$ \\
\hline
\end{tabular}

SNA = it represents the relationship of the Maxilla to the anterior cranial base in anteroposterior direction (angular measurement); SNB = it represents the relationship of the Mandible to the anterior cranial base in anteroposterior direction (angular measurement); ANB = it represents the relationship between the Maxilla and the mandible in anteroposterior direction (angular measurement); GoMe-SN = it represents the relationship of the Mandible to the anterior cranial base in vertical direction (angular measurement); FMA = it represents the relationship of the Mandible to the Frankfort plane in vertical direction (angular measurement); I-SN = it represents the relationship of the maxillary central incisor to the anterior cranial base in anteriorposterior direction (angular measurement); IMPA = it represents the relationship of the mandibular central incisor to the mandible in anteriorposterior direction (angular measurement); $\mathrm{I} / \mathrm{I}=$ it represents the relationship of the mandibular central incisor to the maxillary central incisor (angular measurement); Wits = it represents the relationship between the Maxilla and the mandible in anteroposterior direction (metric measurement).

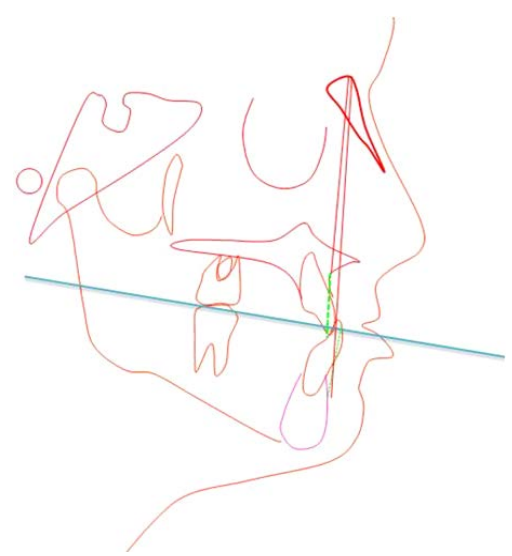

Figure 9. Cephalometric analysis-pretreatemt. * Redlines indicate the major functional components of the face (cranial base, jaws, teeth and facial profile) before orthodontic treatment while blue lines indicate the Functional Occlusal Plane (FOP) as well as the dashed lines indicate $\mathrm{A}$ and $\mathrm{B}$ points projection on the FOP.

Niti arch wire rectangular $(0.016 \times 0.022)$ (Protrusive Arch Wire) was customized to the arch form of the patient. $\mathrm{A} \mathrm{V}$ bend was made mesial to the bondable tubes on first permanent molars. The exposed part of arch wire coated with plastic sleeve to prevent irritation to cheek (Figure 10, Figure 11).

After two weeks orthodontic evaluation has been done of the retroclined upper central incisors which were orthodontically adjusted so the patient could bite in the new situation. The total treatment time was two weeks and the appliance was removed on the end of the second week (Figure 12, Figure 13). 


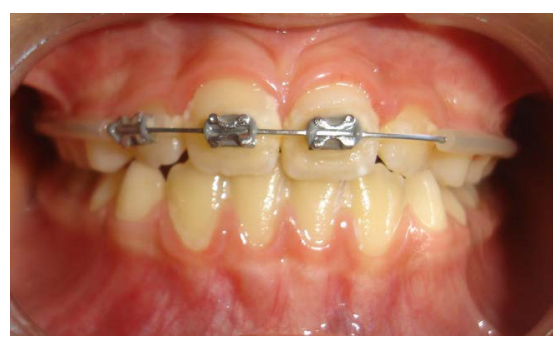

Figure 10. Intraoral view of protrusive arch wire.

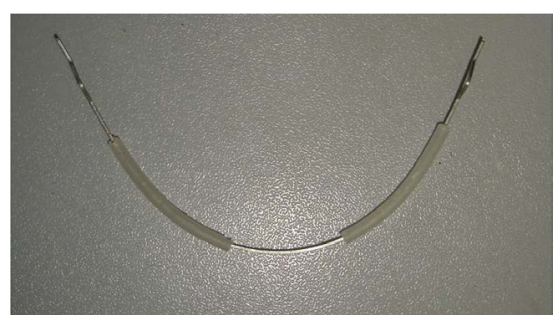

Figure 11. Protrusive arch wire.

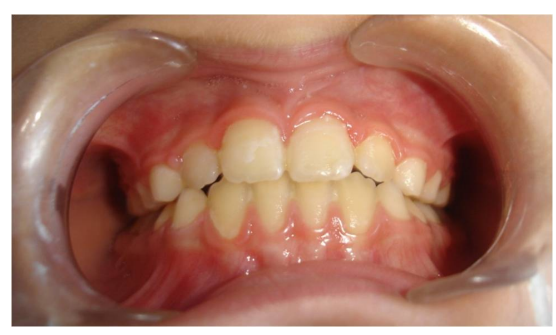

Figure 12. Intraoral view-post-treatment.

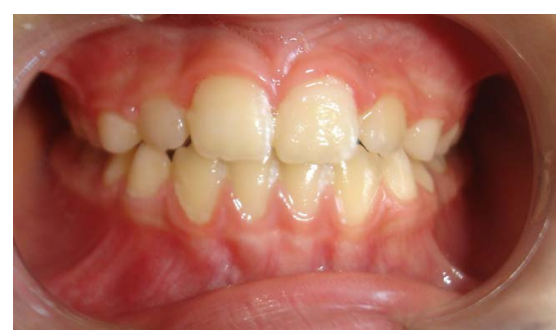

Figure 13. Intraoral view-post-treatment.

A 2-year follow-up for this case with good stability of occlusion, optimal functional and aesthetical states. Final superimpositions showed improvements in ANB and Wits values $(+1$ degree, $-1 \mathrm{~mm})$ respectively. The slight maxillary incisor protrusion coupled with the clockwise mandibular rotation produced an overall improvement of the patient's aesthetic appearance (Figures 14-19).

\section{Discussion}

Typically, an orthodontic case begins with a basic evaluation of the patient's occlusion in static state. The view of occlusion has been enlarged so that it must be thought of as it functions as an integral part of the dynamic masticatory system.

The tooth interference may be more pronounced than premature contact and the mandible may be deflected from its normal functional path, now more than the teeth and supporting tissues are involved and the abnormal function may extend into the temporomandibular joints and musculature [5]. If the interferences cannot be 


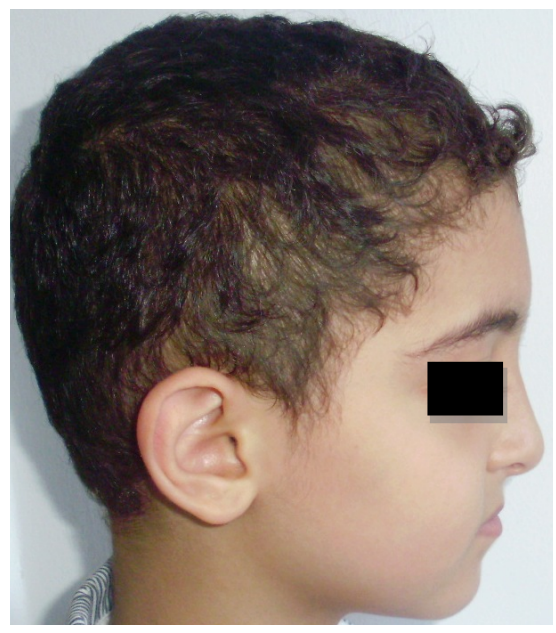

Figure 14. Lateral profile view-post treatment after two weeks.

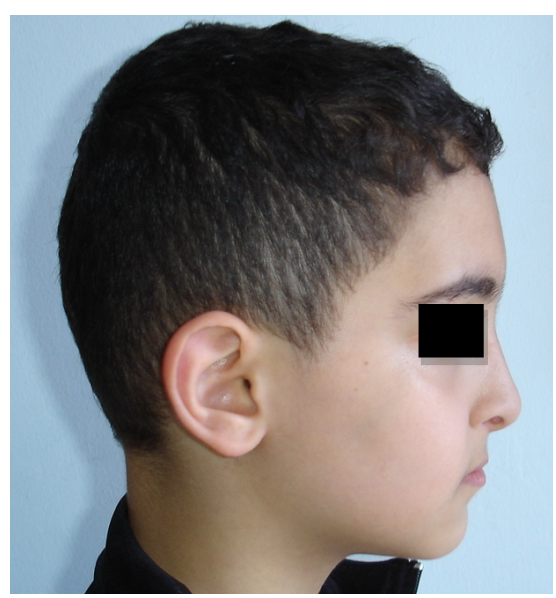

Figure 15. Lateral-profile view-post treatment after 2 years.

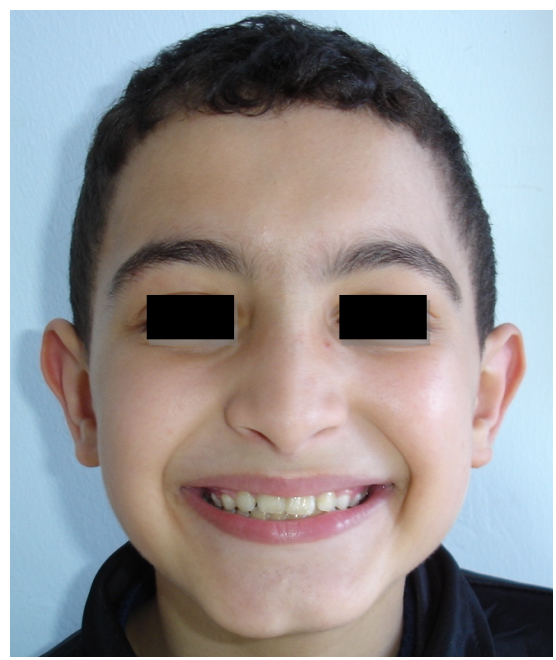

Figure 16. Frontal-extraoral view after 2 years. 


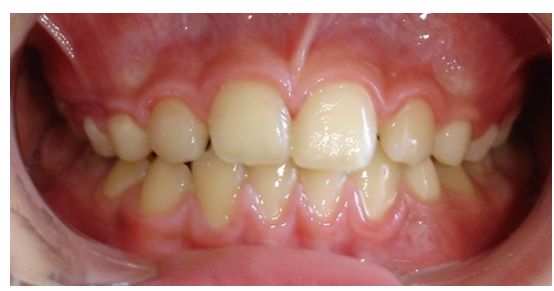

Figure 17. Frontal-intraoral view after 2 years.

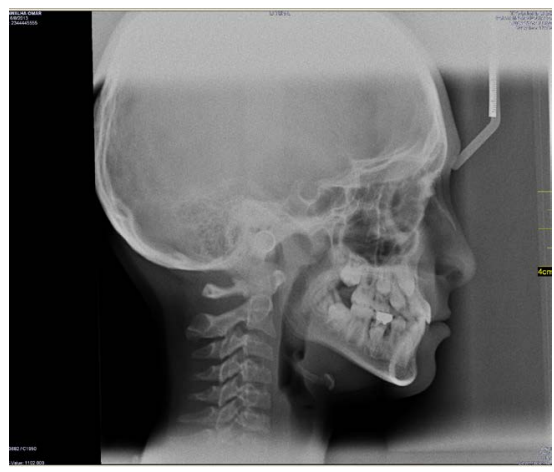

Figure 18. Post-treatment lateral cephalometric radiographs.

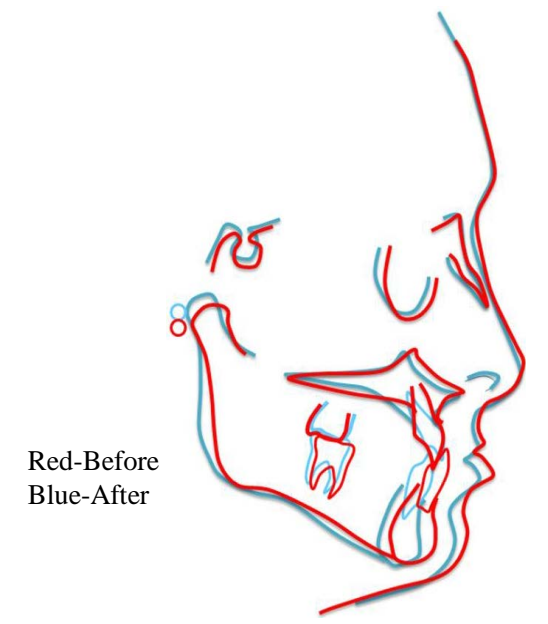

Figure 19. Cephalometric superimposition, showing tracings of the same individual at an earlier (red) and later (blue) time.

avoided comfortably by mandibular displacement in chewing and swallowing by neuromuscular mechanisms (functional adapatation), if the tooth becomes mobile and is moved out of position (structural adapation) and or if the patient cannot ignore the discomfort or the presence of change even for a short period (behavioral adaptation) overt symptoms of dysfunction of the muscles, joints, periodontium or teeth (pulp) may occur [13].

The CR position rarely coincides with MI position in the majority of the population, and about $90 \%$ of people have a deviation up to $1.75 \mathrm{~mm}$ between these two positions [14]. In the cases in which this deviation alters the sagittal relationship between the upper and lower arches, it seems obvious that the diagnosis and orthodontic planning of treatment must be elaborated based on the patient's examination in CR. When this protocol is neglected, one can obtain an incorrect diagnosis and make an incorrect treatment planning for the real malocclu- 
sion. For a clinical example, this error is more common in cases of false class III and unilateral posterior crossbite [15].

In the presented case, as the upper central incisors are retroclined, so there is premature contact which avoided by forward mandibular displacement associated with functional shift to the left to achieve more comfortable bite in centric occlusion (functional adaptation). While, in contrast an edge to edge relationship between upper and lower teeth with posterior open bite when the mandible is manipulated in centric relation which is not comfortable.

In the current case the method used to eliminate the premature contact was not occlusal adjustment by selective grinding which involves the selective reshaping of tooth surfaces that interfere with normal jaw function, it was an orthodontic occlusal adjustment by correction of the position of the retroclined upper central incisors to procline them forward by using the protrusive arch wire [16]-[20].

\section{Conclusions}

1) Functional and structural disturbances in any one of the components of the masticatory system may be reflected by functional or structural disorders in one or more of its other components.

2) Occlusal prematurity can be corrected by fixed orthodontic appliance.

\section{Acknowledgements}

First and foremost I would like to thank my family: Dad "Mohammad Naeem Mahfouz” Mom "Wedad Jarrad" Brother Allam Mahfouz, Sisters, Hanin Mahfouz, Suha Mahfouz, Bayan Mahfouz, Wife Yara Mansour and my kids, Omar Mahfouz, Noor Mahfouz and Sara Mahfouz for their valuable great support, guidance and advice.

\section{References}

[1] Ash, M.M. and Ramfjord, S. (1995) Occlusion. 4th Edition, W.B. Saunders Company, Philadelphia.

[2] Soboḷeva, U., Lauriņa, L. and Slaidiņa, A. (2005) The Masticatory System-An Overview. Stomatologija, Baltic Dental and Maxillofacial Journal, 7, 77-80.

[3] Mohl, N.D. (1988) Introduction to Occlusion. In: Mohl, N.D., Zarb, G.A., Carlsson, G.E. and Rugh, J.D., Eds., A Textbook of Occlusion, Quintessence Books, Chicago, 15-24.

[4] Rugh, J.D. and Smith, B.R. (1988) Mastication. In: Mohl, N.D., Zarb, G.A., Carlsson, G.E. and Rugh, J.D., Eds., A Textbook of Occlusion, Quintessence Books, Chicago, 143-52.

[5] Thompson, J.R. (1956) Function-The Neglected Phase of Orthodontics. The Angle Orthodontist, 26, 129-143.

[6] Brandini, D.A., Trevisan, C.L., Panzarini, S.R. and Pedrini, D. (2012) Clinical Evaluation of the Association between Noncarious Cervical Lesions and Occlusal Forces. The Journal of Prosthetic Dentistry, 108, 298-303. http://dx.doi.org/10.1016/S0022-3913(12)60180-2

[7] Oltramari, P.V., Conti, A.C., Navarro, R. de L., Almeida, M.R., Almeida-Pedrin, R.R. and Ferreira, F.P. (2007) Importance of Occlusion Aspects in the Completion of Orthodontic Treatment. Brazilian Dental Journal, 18, 78-82. http://dx.doi.org/10.1590/S0103-64402007000100017

[8] Wang, C. and Yin, X. (2012) Occlusal Risk Factors Associated with Temporomandibular Disorders in Young Adults with Normal Occlusions. Oral Surgery, Oral Medicine, Oral Pathology, Oral Radiology, 114, 419-423. http://dx.doi.org/10.1016/j.0000.2011.10.039

[9] Strini, P.J., Machado, N.A., Gorreri, M.C., Ferreira, A. de F., Sousa, G. da C. and Fernandes Neto, A.J. (2009) Postural Evaluation of Patients with Temporomandibular Disorders under Use of Occlusal Splints. Journal of Applied Oral Science, 17, 539-543. http://dx.doi.org/10.1590/S1678-77572009000500033

[10] Branschofsky, M., Beikler, T., Schäfer, R., Flemming, T.F. and Lang, H. (2011) Secondary Trauma from Occlusion and Periodontitis. Quintessence International, 42, 515-522.

[11] Dawson, P.E. and Arcan, M. (1981) Attaining Harmonic Occlusion through Visualized Strain Analysis. Journal of Prosthetic Dentistry, 46, 615-622. http://dx.doi.org/10.1016/0022-3913(81)90067-6

[12] de Godoi Machado, N.A., Henriques, J.C.G., Lelis, É.R., Tavares, M., de Araújo Almeida, G. and Fernandes Neto, A.J. (2013) Identification of Occlusal Prematurity by Clinical Examination and Cone-Beam Computed Tomography. Brazilian Dental Journal, 24, 64-67. http://dx.doi.org/10.1590/0103-6440201301974

[13] Ash Jr., M.M. and Nelson, S.J. (2003) Wheeler's Dental Anatomy, Physiology, and Occlusion. 8th Edition, Elsevier Science, Amsterdam, 119. 
[14] Seligman, D.A. and Pullinger, A.G. (2000) Analysis of Occlusal Variables, Dental Attrition, and Age for Distinguishing Healthy Controls from Female Patients with Intracapsular Temporomandibular Disorders. Journal of Prosthetic Dentistry, 83, 76-82. http://dx.doi.org/10.1016/S0022-3913(00)70091-6

[15] Oltramari, P.V., Conti, A.C., Navarro Rde, L., Almeida, M.R., Almeida-Pedrin, R.R. and Ferreira, F.P. (2007) Importance of Occlusion Aspects in the Completion of Orthodontic Treatment. Brazilian Dental Journal, 18, 78-82. http://dx.doi.org/10.1590/S0103-64402007000100017

[16] Mahfouz, M. (2014) Pseudo Class III Treatment in 2-Year-Old Children. Open Journal of Stomatology, 4, 10-13. http://dx.doi.org/10.4236/ojst.2014.41003

[17] Mahfouz, M. (2014) Pseudo Class III Correction in Early Mixed Dentition by Using Protrusive Arch Wire. Journal of Orthodontic Research, 168-172.

[18] Mahfouz, M. (2014) The Current Concepts of Orthodontic Discrepancy Stability. Open Journal of Stomatology, 4, 184-196.

[19] Mahfouz, M. (2014) Face Adaptation in Orthodontics. Open Journal of Stomatology, 4, 315-331.

[20] Mahfouz, M. (2014) The Neglected Phase in Orthodontic Diagnosis and Treatment. Medical Journals—Journal of Oral Hygiene \& Health, 2, 147-152. 
Scientific Research Publishing (SCIRP) is one of the largest Open Access journal publishers. It is currently publishing more than 200 open access, online, peer-reviewed journals covering a wide range of academic disciplines. SCIRP serves the worldwide academic communities and contributes to the progress and application of science with its publication.

Other selected journals from SCIRP are listed as below. Submit your manuscript to us via either submit@scirp.org or Online Submission Portal.
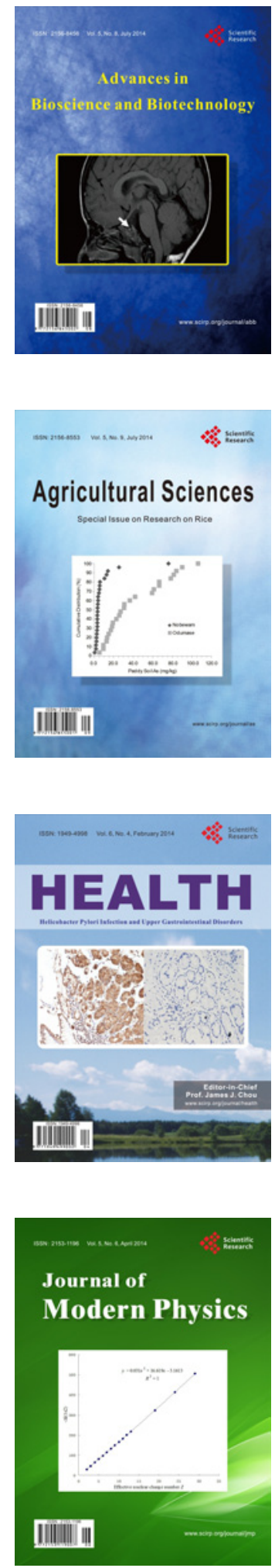
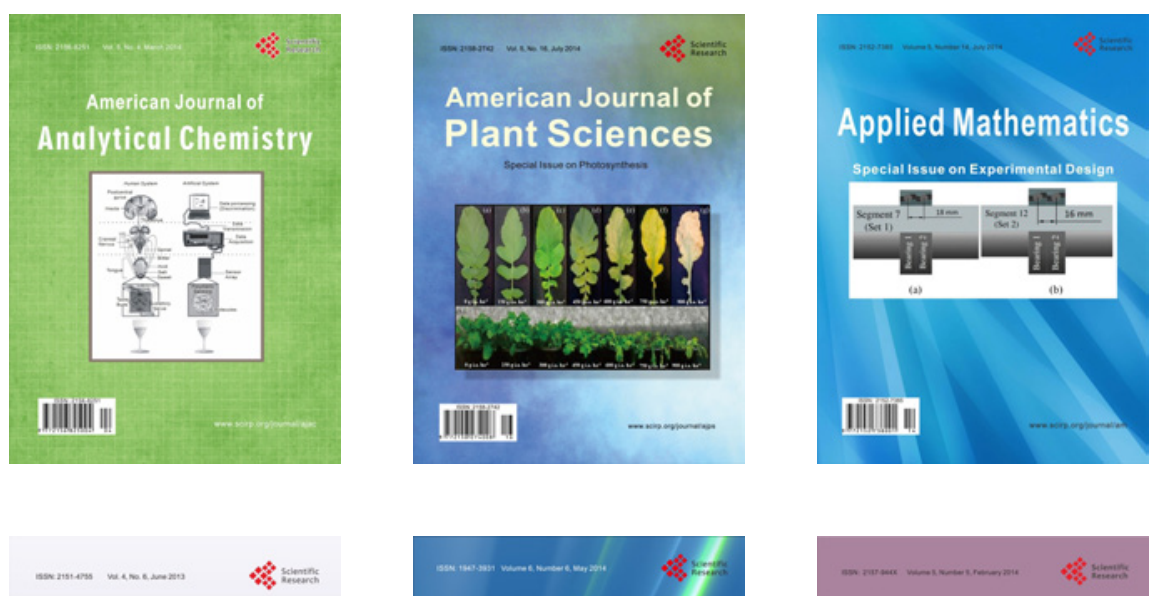

Creative Education
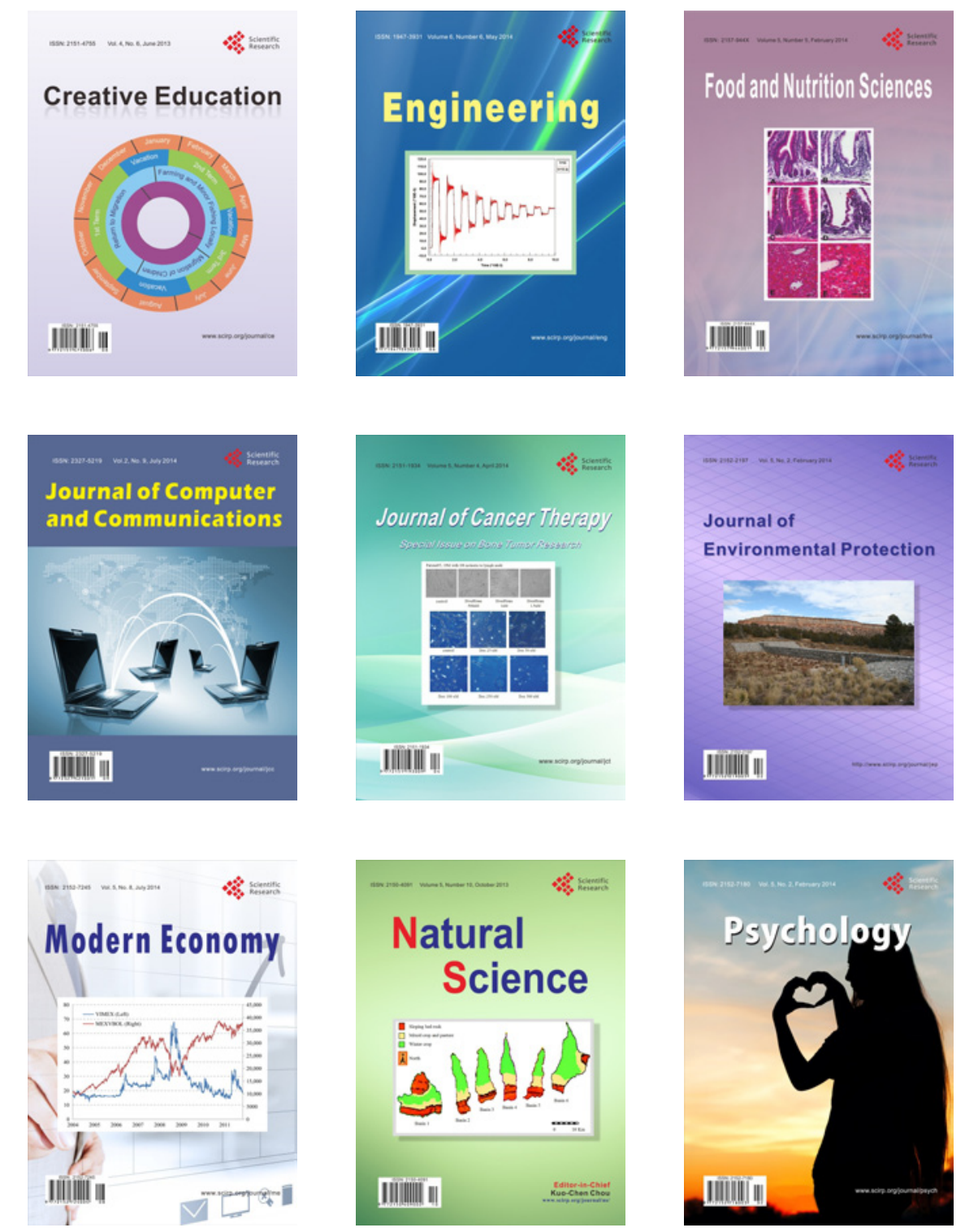